\title{
Map Projection Publications
}

\section{Map Projections Poster}

Describes key properties, characteristics, and preferred uses of many historical and current map projections. 1989. Free.

\section{Miscellaneous Investigations Series M ap I-1402}

The Properties and Uses of Selected Map Projections, by T.R. Alpha and J.P. Snyder. 1982.

Nonmathematical descriptions of 17 common projections. (Supersedes Map I-1096.) Sheet is 31 by 37 inches. Included as an insert in Bulletin 1532 and Professional Paper 1395, or sold separately for $\$ 7.00$.

\section{Professional Paper 1453}

An Album of Map Projections, by J.P. Snyder, U.S. Geological Survey, and P.M. Voxland, University of Minnesota, with an introduction by J.L Morrison, U.S. Geological Survey. 1989, reprint 1994 with corrections. 249 pp.

Brief description of over 90 commonly known and rarely seen map projections. Nonmathematical verbal descriptions with standardized visual portrayals. Precise descriptions of graticules, scale, distortion characteristics, and aspects. Supplemental information on usage, origin, and similar projections. Mathematical formulas in appendix. \$20.00.

\section{Professional Paper 1395}

Map Projections-A Working Manual, by J.P. Snyder. 1987, reprint 1989 and 1994 with corrections, reprint 1997. 383 pp.

Supersedes Bulletin 1532. Title change was due to inclusion of 11 additional projections: Cylindrical Equal-Area, Cassini, Equidistant Conic, Bonne, Gnomonic, General Perspective, Modified-Stereographic Conformal, Satellite-Tracking, Mollweide, and Eckert IV and V. All 16 projections described in Bulletin 1532 are retained. The State Plane Coordinate Systems parameters are listed, not only for the existing North American Datum (NAD) 1927, but also as modified for the NAD 1983. The format of the work is unchanged. General projection concepts are followed by individual projection descriptions that

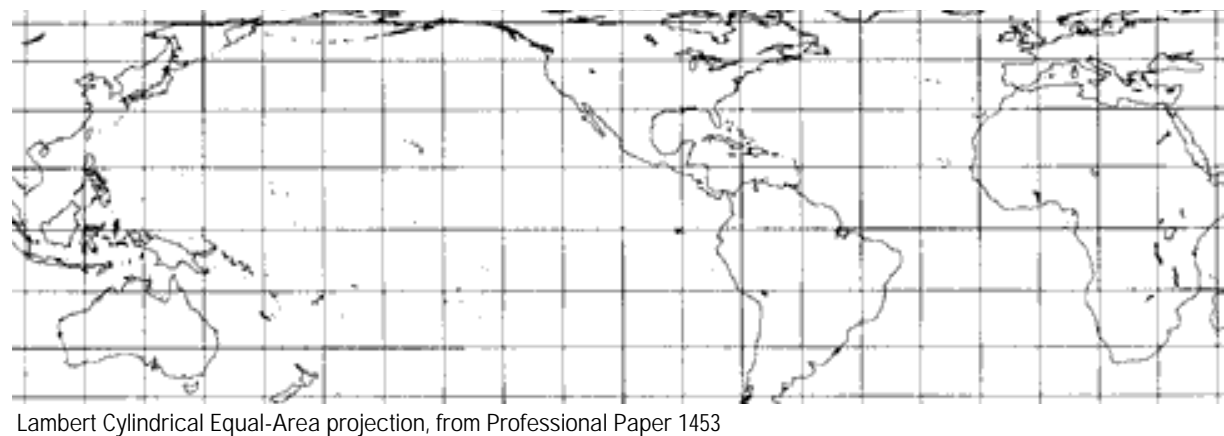

include history, features, usage, forward and inverse formulas for sphere and ellipsoid (where applicable), tables of coordinates, and numerical examples. $\$ 37.00$.

\section{Bulletin 1856}

Bibliography of Map Projections, ed. by J.P. Snyder and H. Steward. 1988. 110 pp.

A comprehensive listing of 2,551 books and papers, with partial annotations by the editor, on map projections from A.D. 150 to 1988, in 28 languages. Extensive subject index. $\$ 5.50$.

\section{Bulletin 1642}

Computer Programs for Common Map Projections, by G.D. Newton. 1985. 33 pp.

Listing of forward and inverse FORTRAN programs for Lambert Conformal Conic, Polyconic, and Transverse Mercator projections. \$2.25.

\section{Bulletin 1532}

Map Projections Used by the U.S. Geological Survey, by J.P. Snyder. 1982, 2d ed., 1983. 313 pp.

Describes 16 projections, including history, features, usage, forward and inverse formulas for sphere and ellipsoid (where applicable), tables of coordinates, and numerical examples. Summary of contents: map projections - general concepts, characteristics, longitude and latitude, the datum and the Earth as an ellipsoid, scale variation and angular distortion, transformation, and classifications. Projections included: Mercator, Transverse Mercator, Oblique Mercator, Miller Cylindrical, Equidistant Cylindrical, Albers Equal-Area Conic, Lambert Conformal Conic, Bipolar
Oblique Conic Conformal, Polyconic, Orthographic, Stereographic, Lambert Azimuthal Equal-Area, Azimuthal Equidistant, Space Oblique Mercator, Van der Grinten, and Sinusoidal. Superseded by Professional Paper 1395 but still suitable for projections covered. $\$ 8.00$.

\section{Bulletin 1518}

Space Oblique Mercator ProjectionMathematical Development, by J.P. Snyder. 1981. 108 pp.

Complete mathematical derivations for the projection developed by the U.S. Geological Survey (USGS) for continuous mapping from Landsat and similar satellites. \$5.50.

\section{Circular 982}

Map Projections Used for Large-Scale Quadrangles by the U.S. Geological Survey, by J.P. Snyder. 1986. 6 pp.

Supersedes USGS Circular 57. Nonmathematical discussion of Polyconic, Transverse Mercator, and Lambert Conformal Conic projections as applied to USGS topographic quadrangles. Free.

\section{Information}

For information on these and other USGS products and services, call 1-888-ASKUSGS, use the Ask.USGS fax-on-demand system, which is available 24 hours a day at 703-648-4888, or visit the general interest publications Web site on mapping, geography, and related topics at http://mapping.usgs.gov/www/products/ mappubs.html.

Please visit the USGS home page at http://www.usgs.gov/. 